\title{
O CENÁRIO DA EDUCAÇÃO INFANTIL APÓS A IMPLANTAÇÃO DO ENSINO FUNDAMENTAL DE NOVE ANOS
}

\author{
THE SCENARIO OF EARLY CHILDHOOD EDUCATION AFTER THE \\ IMPLEMENTATION OF THE NINE-YEAR PRIMARY EDUCATION
}

\author{
Cintia Cristina Escudeiro Biazan \\ Mestre em Educação - Formação e Gestores Educacionais pela Universidade \\ Cidade de São Paulo - UNICID. Santo Paulo, SP, \\ Professora de Educação Infantil e Ensino Fundamental da Prefeitura de Santo André, SP, Brasil. \\ cintia.biazan@gmail.com
}

\begin{abstract}
Maria Aparecida Guedes Monção
Doutora em Educação pela Universidade de São Paulo USP. São Paulo, SP,

Professora do curso de Pedagogia e do Programa de Pós-Graduação em Educação da Faculdade de Educação da Universidade Estadual de Campinas, SP, Brasil. maguedes@unicamp.br
\end{abstract}

\begin{abstract}
Resumo: O objetivo do texto é analisar o cenário da educação infantil em um município paulista com vistas a identificar as marcas da implantação do ensino fundamental de nove anos nas instituições que atendem crianças na faixa etária de 4 a 5 anos. Trata-se de pesquisa qualitativa que utilizou grupo focal como instrumento metodológico e tomou como sujeitos professores e gestores da educação infantil municipal ativos nos anos de implantação do ensino fundamental de nove anos e na educação infantil após as mudanças, precedida de análise das leis e decretos municipais que regulamentam a oferta escolar nesses níveis de ensino. A análise dos dados evidenciou que a educação infantil do município, depois da implantação do ensino fundamental de nove anos, alterou significativamente o cotidiano das crianças, especialmente no que se refere à diminuição expressiva da presença de jogos e brincadeiras na rotina, configurando um cenário marcado por atividades com foco na alfabetização. A pressão por melhores resultados nas avaliações externas no ensino fundamental direcionaram as práticas cotidianas a considerar a preparação das crianças para a entrada no ensino fundamental, um eixo fundante do trabalho pedagógico.
\end{abstract}

Palavras-chave: Educação Infantil. Ensino Fundamental de Nove Anos. Escolarização. Direito à Brincadeira.

\begin{abstract}
The aim of this study is to analyse the scenario of early childhood education in a city of Grande São Paulo in order to identify the marks of the implantation of the nine-year primary education in institutions which serve children aged 4 to 5 years old. This is a qualitative study which made use of a specific group as a methodological instrument, besides, considering teachers and the municipal junior education managers which were active during the intruduction years of fundation school from the age of 9 and on junior eduction after the changes, preceding the analysis of the Laws and municipal ordinance that rule the education offer in these levels of teaching. This analysis of the data showed that the early childhood education in the city after the implementation of the nineyear primary education has changed significantly the children's daily life, especially about the significant decrease in the use of games and children's plays in their routine; as a consequence, there is a scenario marked by activities which focus only in literacy. The pressure for better results at the external evaluations in the primary school guided to daily practices which only takes into account the children preparation for entry into the primary education as the main point to the pedagogical work.
\end{abstract}

Keywords: Children Education. Nine-year Primary Education. Schooling. The Right to Play.

Para citar - (ABNT NBR 6023:2018)

BIAZAN, Cintia Cristina Escudeiro, MONÇÃO; Maria Aparecida Guedes. O cenário da educação infantil após a implantação do ensino fundamental de nove anos Eccos - Revista Cientifica, São Paulo, n. 52, p. 1-17, e13537, jan./mar. 2020. Disponível em: https://doi.org/10.5585/eccos.n52.13537. 


\section{Introdução}

Atualmente, a educação infantil está presente na agenda de discussão de gestores de políticas públicas, profissionais da educação, militantes de diferentes movimentos sociais - em especial os de defesa da educação infantil -, impulsionada por grandes transformações ocorridas na sociedade. Tais mudanças impactaram também a esfera familiar, nas formas de organização de seu cotidiano e de suas diferentes configurações, redefinindo papéis e criando necessidades.

Diante desse cenário, as instituições de educação infantil - creches e pré-escolas ocupam um novo lugar nas políticas educacionais que evidencia a necessidade de ampliar as reflexões a respeito das concepções de infância e educação, para assim alicerçar políticas e práticas voltadas à primeira infância. Ao colocar a creche ao lado da pré-escola no capítulo sobre educação, a Constituição Federal de 1988 (BRASIL, 1988) reforçou os debates e lutas a respeito da concepção de educação infantil em seu caráter público e universal, e de direito de todas as crianças e famílias, além de atribuir ao Estado o dever de ofertar vagas para todos.

Haddad (2002) afirma que o que pode realmente contribuir para um avanço na educação infantil é o reconhecimento de seu caráter multifuncional, integrando suas funções sociais e educacionais, com a finalidade de garantir o desenvolvimento da criança em sua integralidade. Isto se dá por meio da promoção de um ambiente que proporcione segurança, bem-estar e estimule a brincadeira, a interação e o convívio prazeroso entre crianças e adultos e, ainda, assegure às famílias a conciliação do trabalho e das responsabilidades familiares, promovendo a igualdade de acesso e oportunidades entre homens e mulheres, funções que "devem estar em pé de igualdade com a dimensão ensino-aprendizagem e não relegadas a plano secundário.” (HADDAD, 2002, p. 94)

Neste estudo, analisaremos a política de educação infantil, especificamente as questões pertinentes à pré-escola. De acordo com os estudos sobre sua trajetória (KRAMER, 1987; KISHIMOTO, 1988), a concepção mais difundida acerca dessa etapa refere-se à função preparatória para o ensino fundamental. Ao longo da história da educação infantil em nosso país, a pré-escola assume a tarefa de 'entregar' para o ensino fundamental crianças que preencham requisitos e alcancem padrões pré-estabelecidos de aprendizagem para as séries iniciais.

Moss (2011) mostra que a relação entre a educação infantil e o ensino fundamental não é somente de proximidade, mas de poder. Segundo esse autor, a parceria entre níveis de ensino pode ser sólida, mas isso não significa que seja igualitária; há uma relação de subordinação, de 
pressão do ensino fundamental sobre a educação infantil que é traduzida nas políticas públicas e, consequentemente, nas instituições que atendem crianças de 4 e 5 anos.

No Brasil, as mudanças na política pública educacional referentes à ampliação do ensino fundamental para nove anos, aprovada pela Lei n 11.274 (BRASIL, 2006), e à matrícula obrigatória aos 6 anos de idade, pela Lei nº 11.114 (BRASIL, 2005), não partiram de consenso entre os pesquisadores da área, evidenciando divergências com relação à legitimidade do escopo legal e o temor quanto a seus impactos em ambos os níveis de ensino. Há estudos que reputam positivamente essa mudança, tendo em vista a possibilidade de extinguir a divisão entre as duas modalidades (KRAMER, 2006; KRAMER; NUNES; CORSINO, 2011); há os que discordam e a consideram um recuo nos direitos das crianças de 0 a 6 anos que já haviam sido conquistados na educação infantil. (ARELARO; JACOMINI; KLEIN, 2011; BARBOSA; DELGADO, 2012; KLEIN, 2011)

Considerando a importância dessa temática para a área e a necessidade de ampliar os estudos sobre os impactos da inserção das crianças de 6 anos no ensino fundamental nas instituições de educação infantil, este artigo objetiva analisar o cenário da educação infantil em um município da Grande São Paulo, com vistas a identificar as marcas da implantação do ensino fundamental de nove anos nas instituições que atendem crianças de 4 e 5 anos. Trata-se de pesquisa qualitativa, cujo estudo empírico foi realizado em uma rede municipal de educação que atende educação infantil e ensino fundamental. A primeira etapa da educação básica no município é dividida em dois tipos de atendimento, com prédios e propostas pedagógicas distintas: as creches recebem os bebês e crianças de 0 a 3 anos e as escolas municipais de educação infantil e ensino fundamental (Emeief) são integradas, atendendo crianças de 4 e 5 anos, que dividem o mesmo espaço com as de 6 a 10 anos.

Os dados foram coletados por meio de análise documental e grupo focal. A análise documental envolveu a leitura de leis e decretos municipais que possibilitaram compor um panorama da política de educação infantil no município pesquisado. Já o grupo focal permitiu compreender a visão dos profissionais de educação acerca da implantação das leis $\mathrm{n}^{\circ} 11.114 \mathrm{e}$ no 11.274 (BRASIL, 2005, 2006) na rede. Sobre essa técnica de coleta de dados, Gatti (2012) afirma que, por meio da sequência de falas e das trocas entre os participantes, procura-se compreender o impacto no grupo sobre as vivências com o tema, explicitando consensos, dissensos, silêncios, momentos eufóricos, descontinuidades.

Devido à singularidade do estudo, o grupo foi formado por professoras da rede pública municipal que atuavam na docência ou na gestão da educação infantil em 2005 e 2006 e que 
permaneceram nesse nível de ensino após a aprovação das citadas leis até o momento da pesquisa.

O desenvolvimento do trabalho baseou-se nos princípios éticos da pesquisa em educação. Todas as profissionais foram devidamente informadas quanto ao teor da investigação e consultadas sobre seu interesse em participar. Ao concordar em participar da pesquisa, cada sujeito assinou o termo de consentimento livre e esclarecido. Firmou-se o compromisso de assegurar a privacidade em relação aos dados coletados. Assim, os cargos ocupados pelas participantes são reais, mas os nomes utilizados para identificá-las são fictícios.

A análise dos dados foi estruturada em dois eixos. O primeiro trata do percurso da educação infantil no município, buscando explicitar a trajetória das instituições de educação infantil, sua estrutura e diretrizes. O segundo eixo - conteúdo analítico apresentado neste artigo - aborda a relação entre o ensino fundamental de nove anos e a educação infantil, analisando as mudanças ocorridas na organização do trabalho pedagógico das instituições de educação infantil que atendem crianças de 4 e 5 anos após a implantação das Leis $n^{\circ} 11.114$ e n ${ }^{\circ} 11.274$. (BRASIL, 2005, 2006)

O texto está organizado em duas partes. Inicialmente, discutiremos as especificidades da educação infantil e o ensino fundamental de nove anos; em seguida, analisaremos os dados advindos da pesquisa, evidenciando as marcas do ensino fundamental de nove anos nas turmas de 4 e 5 anos da educação infantil do município pesquisado.

\section{A especificidade da educação infantil e o ensino fundamental de nove anos}

De acordo com as Diretrizes Curriculares Nacionais para a Educação Infantil (DCNEI) (CONSELHO NACIONAL DE EDUCAÇÃO, 2009), a proposta curricular das instituições para esse nível de ensino tem como eixo central as brincadeiras e as interações e a escola infantil apresenta um caráter diferente dos outros níveis de ensino. Ela não é uma instituição em que se ministram às crianças aulas com o mesmo tema, com a intenção de que elas aprendam o mesmo conteúdo e ao mesmo tempo. Os conteúdos nessa etapa da vida devem ser amplos e não obedecem a uma ordem a ser seguida que determine a passagem da criança para outros estágios.

Os estudos da Sociologia da Infância (BARBOSA; DELGADO; TOMÁS, 2016; CORSARO, 2011; SARMENTO; PINTO, 2004) contribuem para refletir sobre a constituição de outras bases para efetivar o trabalho com a criança pequena e possibilitam uma nova forma de compreendê-la ao valorizar suas potencialidades e as culturas infantis que representam, deixando de vê-la por suas fragilidades. Os estudos destacam a criança pequena como capaz de 
estabelecer múltiplas interações e participar ativamente em sua formação, o que mostra a importância e a potência da cultura de pares.

Nesse sentido, é fundamental que as políticas públicas de educação infantil adotem como referência os estudos da infância e da criança, para a organização das instituições de educação infantil. Barbosa, Delgado e Tomás (2016, p. 107) assinalam:

[...] as relações das crianças entre elas e o papel que o encontro, o convívio e os relacionamentos têm do ponto de vista social e individual, são especialmente importantes para que conheçamos seus critérios de pertencimento em alguns grupos, quase nunca marcados pelas faixas de idade, uma vez que esses critérios são demarcações adultocêntricas.

O adultocentrismo, presente historicamente na organização e estruturação das creches e pré-escolas brasileiras, é um dos empecilhos para legitimar políticas públicas de educação infantil em que a criança assuma seu papel de centralidade e protagonismo na proposta educativa. O cotidiano das instituições é marcado pela organização de um trabalho pedagógico

[...] distante da cultura infantil e dos direitos fundamentais das crianças. Na maioria das instituições, prevalece a organização de tempos e espaços centrada nos adultos, explicitada por meio de rotinas padronizadas que não levam em conta a subjetividade das crianças pequenas e que favorecem o estabelecimento de relações de dominação do adulto sobre a criança. Além disso, há nas instituições de educação infantil uma rejeição das atividades relacionadas aos cuidados de higiene e alimentação, por parte dos profissionais, que não as classificam como ações pedagógicas. (MONÇÃO, 2013, p. 37)

Apesar do amparo legal e dos estudos sobre a infância, as alterações da política pública nem sempre consideram as especificidades da educação infantil para implementar nova organização ao sistema de ensino. Nesse sentido, pode-se tomar como exemplo a lei que deslocou as crianças de 6 anos da educação infantil para o ensino fundamental. Em 2005, foi aprovada a Lei $\mathrm{n}^{\circ} 11.114$ (BRASIL, 2005), que redefiniu a faixa etária de ingresso, tornando obrigatório o início no ensino fundamental a todas as crianças de 6 anos. Esse encaminhamento não foi discutido com educadores e pesquisadores, não houve nenhum tipo de consulta pública à sociedade civil, ao Conselho Nacional de Educação (CNE) ou ao Ministério da Educação (MEC) (ARELARO, 2005; BARBOSA; CRAIDY, 2012), demonstrando o imenso desrespeito aos processos democráticos e à estrutura do sistema educacional. Não houve preocupação sobre se os sistemas teriam vagas ou estrutura pedagógica suficientemente preparada para receber esse número de crianças, como se isso fosse uma transição tranquila e os dois níveis de ensino fossem semelhantes. Pode-se deduzir que, com a aprovação dessa lei, pretendia-se encontrar uma maneira de utilizar os recursos do Fundo de Manutenção e Desenvolvimento do Ensino Fundamental e de Valorização do Magistério (Fundef) com as crianças menores, tendo em conta a dificuldade dos municípios de ampliar sua rede de educação infantil. No ano seguinte, foi 
aprovada a Lei $n^{\circ} 11.274$ (BRASIL, 2006), que ampliou o ensino fundamental para nove anos de duração, aumentando o número de matrículas de crianças no sistema educacional brasileiro, especialmente aquelas pertencentes aos setores populares.

No entanto, temos de considerar que a política objeto de estudo desta pesquisa foi formulada exclusivamente pensando na extensão do ensino fundamental para inclusão das crianças de 6 anos nessa etapa de ensino. Tais crianças, segundo Klein (2011), não foram pensadas em suas características e em sua infância nem consideradas na efetiva realização da mudança. A autora salienta que as crianças de 6 anos foram tratadas como 'objeto' da política educacional e por isso puderam ser lançadas de uma etapa de ensino para a outra sem maiores estudos ou pesquisas sobre a questão.

Em consequência dessa falta de estrutura e comprometimento com as mudanças que ocorreriam com tal reforma, pode-se afirmar que a implantação do ensino fundamental de nove anos gerou inúmeros contratempos, tais como: ausência ou insuficiência dos cursos de formação continuada para os professores que assumiriam as novas turmas no ensino fundamental; falta de adequação dos espaços escolares para receber as crianças de 6 anos; alterações pouco significativas nos currículos; cobranças mais sistemáticas para a alfabetização. Contudo, esse ingresso, focado apenas na vertente financeira, foi realizado sem uma proposta pedagógica adequada e sem ouvir os maiores envolvidos no processo: crianças, famílias e educadores.

\footnotetext{
Se considerado que a aprovação das duas Leis federais (Leis $\mathrm{n}^{\circ} 11.114 / 05$ e $\mathrm{n}^{\circ}$ 11.274/06) aconteceu de forma isolada e que a primeira visou apenas antecipar a entrada das crianças no ensino fundamental (o que posteriormente desencadeou a segunda lei), pode-se afirmar que a matrícula das crianças de seis anos no ensino fundamental e o ensino fundamental de nove anos foram gestados nos marcos do Fundef, onde os interesses econômicos sobrepunham-se aos pedagógicos. (KLEIN, 2011, p. 69)
}

A desvalorização dos investimentos financeiros nas outras etapas e modalidades que não fossem o ensino fundamental foi outro grande impacto do Fundef. A educação infantil, etapa que atendia oficialmente a crianças de 0 a 6 anos de idade, ficou desassistida de recursos. $\mathrm{O}$ financiamento proposto para a educação freava os investimentos na ampliação e melhoria na qualidade daquele nível de ensino. De acordo com Klein (2011), a solução viável e mais rentável era a matrícula de crianças de 6 anos no ensino fundamental, garantindo maior percentual de investimentos, opção realizada pela maioria das redes de ensino. Posto dessa forma, os alunos passaram a ser vistos como 'unidades monetárias', uma vez que não se visava melhoria pedagógica: o que interessava de fato eram os recursos financeiros atrelados a cada uma das matrículas efetuadas. 
Inserir as crianças de seis anos no ensino fundamental sem considerar a importância da brincadeira, das interações e da integração entre as ações de cuidado e educação, no contexto das instituições de educação infantil, reforça a perspectiva de uma pedagogia transmissiva focada em uma prática pedagógica burocratizada, que não atenta para o processo e a subjetividade do educando e do educador. Tais fatores provocam uma negação da especificidade das instituições de educação infantil, ao ignorar o fato de que a criança pequena aprende experimentando, investigando, brincando, na interação com os adultos - educadores e famílias - e com outras crianças. Na perspectiva transmissiva, ao invés disso, valorizam-se as ações do professor sobre a criança, desconsiderando a importância e o potencial de suas interações entre si, tão enfatizadas nas atuais pesquisas sobre as instituições de educação infantil.

\section{As marcas do ensino fundamental de nove anos na educação infantil de um município da Grande São Paulo}

A passagem das crianças de 6 anos da educação infantil para o ensino fundamental aconteceu, em um primeiro momento, de maneira quase imperceptível nas instituições públicas do município pesquisado. Os representantes da Secretaria Municipal de Educação, nas reuniões com as equipes gestoras, afirmavam que não haveria alteração na rotina das turmas de 6 anos nem nas turmas de educação infantil, uma vez que não era essa a proposta, mas sim incorporar nas práticas cotidianas do ensino fundamental a ludicidade presente nesse nível de ensino. Uma das participantes do grupo focal comenta:

Se ampliou um ano, mas o que vamos fazer? Eu lembro que nas reuniões eles [Secretaria de Educação] diziam assim: nós estamos ampliando um ano, isso não é para escolarizar o infantil, mas para infantilizar o ensino fundamental. (Professora Laura)

As participantes do grupo focal destacaram ter havido mudanças na rotina, na organização do espaço e ambiente da educação infantil de 4 e 5 anos quando as referidas leis foram implantadas. No entanto, isso não aconteceu de uma hora para outra nem ocorreu depois de uma diretriz, orientação ou formação oferecida pela rede; a transformação do trabalho pedagógico com as crianças de 4 e 5 anos ocorreu lentamente, com o passar dos anos:

Sim, totalmente. Eu percebo assim... Que não tem mais tão presente o trabalho com música, o trabalho com artes, o trabalho com tinta quase que imperceptível. É um ou outro professor que desenvolve na sala. (Gestora Alexia)

Mas eu acho que o próprio ambiente da Emeief, porque ele mudou [...] Esse ambiente ficou institucionalizado. [...] A estrutura física da escola mudou, então o professor acaba estando na mesma condição e eu sei disso como gestora. (Gestora Tatiana) 
De acordo com as participantes, as salas da educação infantil com espaços amplos foram divididas em duas para atender à demanda por matrículas no ensino fundamental; os parques de areia foram substituídos por parques de madeira, com brinquedos grandes, inadequados para a faixa etária de 4 e 5 anos. Tais alterações evidenciam que nas Emeief, apesar de se contemplar a educação infantil, a prioridade é o ensino fundamental:

A gente perdeu o parque de areia, foi uma perda muito grande pra aquela escola e a
gente conquistou esse parque novamente depois de quantos anos? Eu nem sei, perdi a
conta. Foi uma briga muito grande, demorou anos e por quê? Porque não era
prioridade! [...] E não foi um único espaço, nós perdemos vários espaços, nós
perdemos o parque de areia, a casinha que precisou sair para dar lugar àquele
puxadinho no pátio. O parque estava novo! Nós perdemos o tanque de areia, a casinha
e os cantos que eram montados dentro das salas de aula. (Professora Mariana)

Sobre a organização dos espaços físicos e de como esses ambientes podem revelar se foram pensados e propostos para as crianças, Barbosa (2010, p. 8) afirma:

[...] o espaço físico da escola nos ensina que os ambientes têm uma linguagem silenciosa, porém potente. Eles nos ensinam como proceder, como olhar, como participar. [...] Cada um destes ambientes nos apresenta uma concepção de infância, de educação e cuidado. Os ambientes são a materialização de um projeto educacional e cultural. [...] O parquinho da escola é um espaço que deve ser pensado e organizado na medida das crianças [...] Acima de tudo, o espaço em que as crianças vivem tanto tempo precisa ser prazeroso, bonito, relaxante, alegre.

Além das mudanças nos espaços físicos, as participantes identificaram as avaliações externas efetivadas no ensino fundamental como fator determinante para que a rotina e as práticas pedagógicas da educação infantil se tornassem mais institucionalizadas após a efetivação das Leis $n^{\circ} 11.114$ e nº 11.274 (BRASIL, 2005, 2006), tendo em vista a grande preocupação com relação aos conteúdos de leitura, escrita e matemática, de que os estudantes devem apropriar-se nas séries iniciais. O grupo aponta que as professoras do ensino fundamental exercem uma cobrança velada para que as crianças da educação infantil cheguem ao $1^{\circ}$ ano com um conhecimento mínimo, para que elas possam dar continuidade ao trabalho e alcancem os níveis exigidos em avaliações externas. De maneira geral, os depoimentos mostram que essas avaliações desencadearam a necessidade de quantificar a aprendizagem das crianças, deflagrando inquietações entre as professoras acerca de como seria possível permanecer com a dimensão lúdica da educação infantil e um $1^{\circ}$ ano seguindo a mesma lógica se o processo de avaliação dessas práticas ocorre de maneira hierarquizada, sem considerar a especificidade da educação infantil ou as peculiaridades do processo de alfabetização das crianças no ensino fundamental. 
E muitas vezes o professor se perde nisso também, ele se cobra, se sente péssimo, mas ao mesmo tempo ele não quer ser visto como um mau professor... (Professora Laura)

Fica um dilema interno. O professor fica desesperado. [...] A gente sabe... Vamos ser avaliados. Então você fica pensando: Nossa, a professora do ano que vem! (Gestora Tatiana)

E uma coisa que eu percebo que mudou nesses anos [...] a gente acaba muitas vezes trabalhando para o outro e para o outro é para o ano seguinte. Para o professor que vem depois. Até eu, eu me vejo fazendo muito isso, ao invés de pensar na criança... Ah... Mas eu preciso fazer isso pensando já no que vem pela frente. Acho que isso é uma coisa que dá pra gente avaliar também nesse período todo aí, o que mudou de ruim. (Professora Maria Clara)

Não, não dá, não dá pra ser como antes [da implantação das leis]. (Professora Júlia)

Sem contar que tem um monte de coisas que não são mais desenvolvidas na educação infantil, porque eu preciso dar conta de trabalhar as letras do alfabeto, os numerais e lá, lá, lá... Então eu não ensino mais pra eles as brincadeiras regradas, as cantigas de rodas, eu não faço mais esse resgate com os meus alunos e eles não brincam mais com isso com ninguém. (Gestora Alexia)

O destaque maior nas falas das participantes refere-se à substituição, no cotidiano da educação infantil, das brincadeiras por atividades de escolarização, ou seja, "atividades de folhinha" (Gestora Alexia) com foco no "desenvolvimento cognitivo" (Professora Maria Clara), o que, na avaliação das participantes, não garante a melhora do desempenho das crianças no $1^{\circ}$ ano do ensino fundamental. Ao serem convidadas a aprofundar a reflexão sobre essa temática, elas dizem:

E sabe o que me preocupa com essas atividades de folhas, por exemplo, ela é muito, muito estanque, né? [...] Eles [crianças] precisam viver, eles precisam vivenciar o que a gente está desenvolvendo com eles. Então, antes de eu fazer qualquer coisa no papel, eu preciso propor experiências para que eles sintam, tenham contato com aquilo que eu estou desenvolvendo, senão não irá sair nada! [risos]. Ela tem que ser significativa. Ou aí acaba virando um registro de cópia, que é o que a gente não quer, mas é o que acontece. (Gestora Alexia)

Eu acho que precisam saber de onde veio e para onde vai, né? A atividade em si, dependendo de quem está aplicando, ela vai morrer ali, ela vai se esgotar ali. (Professora Maria Clara)

As participantes afirmaram que a prioridade da educação infantil atualmente são as atividades de cópia e treino de letras. Os depoimentos revelam que o processo de alfabetização previsto na legislação para o ensino fundamental está acontecendo cada vez mais cedo nas turmas de educação infantil, com o pressuposto de preparar as crianças para o ensino fundamental e garantir o atendimento de todas as exigências desse nível de ensino. Tais considerações vão ao encontro do estudo realizado por Corrêa (2011) sobre o processo de ampliação do ensino fundamental e seus reflexos na educação infantil. A pesquisadora afirma que há uma antecipação dos conteúdos de alfabetização e conhecimentos matemáticos destinados ao ensino fundamental, por meio de atividades mecânicas de cópia de letras e 
números, resultando em rotinas na educação infantil que não correspondem às necessidades das crianças de 4 a 5 anos.

A ênfase em atividades preparatórias à inserção no ensino fundamental fragiliza a identidade das instituições de educação infantil e nega suas especificidades, ao desconsiderar as brincadeiras e as interações como eixo central das propostas pedagógicas, tal como preconizado na DCNEI (CONSELHO NACIONAL DE EDUCAÇÃO, 2009), para dar ênfase à alfabetização:

Pois é, ele [criança] acabou de fazer 5 e aí já estamos preocupados com a fase da escrita. Ele tem todos os dias atividades de escrita. [...] Hoje, na turma de 6 anos, o conteúdo é a nossa antiga $1^{\text {a }}$ série, a turma de 5 faz hoje o que a turma de 6 fazia, e assim por diante. [...] Eles chegam imaturos para realizar as atividades que estão realizando, ele quer brincar, ele não quer escrever as letras do alfabeto. Mas no ano que vem ele vai para o $1^{\circ}$ ano, então ele tem que estar preparado. (Professora Larissa)

A educação infantil da nossa escola está mais escolarizada, não sei se esse é o termo, mas está mais focada na escrita do que no corporal, no lúdico. (Professora Mariana)

Eu acho que não precisa massacrar a criança, o que está acontecendo hoje, e fazer com que elas fiquem copiando da lousa. Eu não sei... Eu acho que é uma coisa pra refletir mesmo. (Gestora Alexia)

A organização do tempo, dos espaços, dos materiais e do ambiente é fundamental para se promoverem experiências significativas que favoreçam o desenvolvimento integral da criança. É necessário que nesse ambiente as brincadeiras e as interações sejam consideradas o eixo norteador de todo o trabalho pedagógico, e o cuidado e a educação sejam compreendidos e efetivados de forma indissociável. Para Kishimoto (2010, p. 1),

O brincar é uma ação livre que surge a qualquer hora, iniciada e conduzida pela criança, dá prazer, não exige, como condição, um produto final, relaxa, envolve, ensina regras, linguagens, desenvolve habilidades e introduz no mundo imaginário [...] sua importância se relaciona com a cultura da infância, que coloca a brincadeira como a ferramenta para a criança se expressar, aprender e se desenvolver.

O respeito e a garantia à brincadeira são funções essenciais da educação infantil. Não apenas pelo fato de que essa prática social se apresenta na infância com maior intensidade, mas por ser ela a experiência inaugural de sentir o mundo e experimentar-se, de aprender a criar e inventar linguagens pelo exercício lúdico da liberdade de expressão. De acordo com Sarmento (2004, p. 15):

\footnotetext{
A ludicidade constitui o traço fundamental das culturas infantis. Brincar não é exclusivo das crianças, é próprio do homem e uma das suas atividades sociais mais significativas. Porém as crianças brincam, contínua e abnegadamente. Contrariamente aos adultos, entre brincar e fazer coisas sérias não há distinção, sendo o brincar muito do que as crianças fazem de mais sério.
} 
Ademais, de acordo com Corrêa (2011), as práticas de memorização e repetição de conteúdo para a aquisição da língua escrita no próprio ensino fundamental têm sido objeto de crítica entre pesquisadores da área, dado seu caráter limitador das possibilidades de expressão entre as crianças, evidenciando uma pedagogia centrada na figura do professor e na exposição e memorização de conteúdos que são assimilados por meio do treino e da repetição por parte das crianças. Se mesmo no ensino fundamental tal postura é questionada, na educação infantil torna-se totalmente inadequada. Corrêa (2011) enfatiza que tais práticas não surgiram com a antecipação da entrada das crianças de 6 anos no ensino fundamental, mas ocorrem há muito tempo; no entanto, essa nova organização revelou que elas resistiram ao longo do tempo e atualmente são a prioridade nas turmas de educação infantil de 4 e 5 anos.

Outro aspecto identificado nos depoimentos das participantes sobre os impactos da implantação do ensino fundamental de nove anos na educação infantil são as debilidades presentes na formação inicial e continuada dos professores, considerando as especificidades da educação infantil. As professoras destacaram a necessidade de investir na formação continuada, considerando sua importância para promover a reflexão sobre a prática pedagógica e garantir o caráter coletivo do trabalho:

[...] eu acho que os professores, se a gente for olhar atualmente, comparando com alguns anos atrás, né, eu vejo que os professores que têm vindo para as escolas atualmente, eles têm uma formação muito rasa, mas muito rasa mesmo, do que tem que fazer na sala de aula com as crianças. Então, não tem formação voltada para a educação infantil, não tem! (Gestora Alexia)

$\mathrm{Eu}$ acho que faltou investimento na formação do professor que se dedica a essa modalidade, tanto inicial como em serviço, né? (Gestora Tatiana)

Sim, faltou [formação continuada] em favor do aluno! Não em favor do ano seguinte, não em favor da Provinha Brasil! (Professora Maria Clara)

As participantes do grupo focal assinalaram que a divisão existente na rede municipal entre creche e Emeief impacta também a formação continuada nas unidades educacionais que atendem crianças com 4 e 5 anos, pois as reuniões pedagógicas semanais (RPS) apresentam conteúdos diferentes dos tratados nas creches, como também dos objetivos das instituições de educação infantil de maneira geral, como é preconizado pelas DCNEI (CONSELHO NACIONAL DE EDUCAÇÃO, 2009) e ilustrado pelo depoimento de uma das professoras do grupo focal: 
Eu já trabalhei com a mesma faixa etária em creche e em Emeief e é muito diferente porque o tipo de discussão de RPS é diferente [...] o tipo de cobrança é diferente. Porque a formação que até o [assistente pedagógico] AP dá nesses espaços é diferente. Lá na creche ele vai estar olhando o desenvolvimento como um todo, desde o bebezinho, até os 4 anos. Lá [Emeief] não, a discussão será a fase da escrita, porque a professora do $1^{\circ}$ ano está se descabelando porque as crianças não estão conseguindo reconhecer as letras, né? [...] Então, esses espaços influenciam muito, devido ao nível de discussão e ao foco de observação. (Professora Laura)

As participantes do grupo focal indicaram a predominância das formações pautadas na temática da alfabetização e apontaram o Pacto Nacional pela Alfabetização na Idade Certa (Pnaic) como um dos fatores que ajudou a contribuir para esse viés. Toda a rede municipal foi convidada a participar dessas formações, que foram realizadas fora do horário de trabalho. Os professores que atuavam no primeiro ciclo do ensino fundamental recebiam uma bolsa auxílio para cursarem o Pnaic. Os docentes que atuavam no segundo ciclo do ensino fundamental e na educação infantil, mesmo em creche, podiam fazer o curso com dispensa de metade da carga horária da RPS, e todos recebiam certificado. Com esses incentivos, grande número de docentes - mesmo os que não atuavam no primeiro ciclo - aderiu ao Pnaic e a alfabetização na idade certa passou a ser o assunto mais discutido nas RPS do município.

Eu trabalhei dois anos nas salas de educação infantil [...] e mudou totalmente daquela época para cá. Educação infantil hoje na escola tá escolarizada, o foco não é a criança, o foco é a alfabetização e eu acho que o Pnaic, que agora nesses últimos anos, ele veio reforçar isso e não o contrário, né? Porque, se você vê os direitos de aprendizagem do $1^{\circ}$ ano, é muito alto. (Professora Larissa)

Quando questionadas se houve formação continuada específica para a educação infantil desde a transição das crianças de 6 anos para o ensino fundamental, objetivando refletir sobre as práticas pedagógicas com as crianças de acordo com a especificidade dessa etapa, as participantes da pesquisa negaram ter havido.

Em sua pesquisa, Corrêa (2003) também constatou a existência de poucos investimentos na formação em serviço no âmbito das unidades escolares, entendendo esse fator como reflexo de políticas que reforçam o individualismo, ao incutir a ideia de que cada um é responsável pela qualidade do seu trabalho, de forma isolada.

Mas independentemente de processos coletivos de discussão e reflexão realizados pelas próprias professoras de educação infantil, a situação atual faz crer na necessidade de inclusão, seja nos currículos dos cursos de formação inicial, seja nos programas de formação em serviço, de conteúdo que garanta o conhecimento acerca do que seja a dimensão de cuidado da criança pequena em suas diferentes nuanças e perspectivas e, sobretudo, acerca de seus direitos. (CORREAA, 2003, p. 110)

Refletindo ainda sobre a formação continuada para a educação infantil, as participantes relataram que no ano de 2016 a rede propôs uma formação denominada Encontro com os Assistentes Pedagógicos ${ }^{1}$, cuja meta era a discussão com as professoras de educação infantil 
das Emeiefs sobre concepção de educação infantil, tendo como disparador da discussão a análise dos Indicadores de Qualidade da Educação Infantil. Uma das gestoras participantes do grupo focal pondera:

[...] esse encontro com as APs, ele tinha um foco mais voltado para a educação infantil sim, porém a gente ainda tá muito naquela discussão da concepção, e aí você tem que levar para o grupo de professores também, porque esse é o foco. Eu fiz com os professores esse ano aqui e eu achei que foi bacana [...] são os indicadores de qualidade na educação infantil. Ele é um material muito bom, pra gente analisar, avaliar o trabalho que a gente faz, o trabalho de educação infantil que a gente tem feito na escola com relação a tudo, com relação ao espaço, as relações que você propõe ali para os alunos, como que acontecem essas relações. O que eu não estou fazendo e o que eu preciso melhorar. [...] porém esse encontro não é quinzenal, começou mensal e ultimamente tem uns dois meses que a gente não teve ele. (Gestora Alexia)

As participantes da pesquisa concluíram que, ao longo dos anos, as formações voltadas para a educação infantil aconteceram de forma isolada e foram pouco significativas para garantir os pressupostos assinalados nas DCNEI. Segundo Kramer (2006, p. 806):

[...] os processos de formação configuram-se como prática social de reflexão contínua e coerente com a prática que se pretende implementar. Cursos esporádicos e emergenciais não resultam em mudanças significativas, nem do ponto de vista pedagógico, nem do ponto de vista da carreira.

Em se tratando de formação de professores, em especial de professores que atuam com a educação infantil, Haddad (2006, p. 540) ressalta que ela deve ser centrada pensando na criança de maneira integral, em todas as suas linguagens e conhecimentos:

A formação de quem cuida das crianças pequenas e as educa não pode ser aquela que visa apenas ao acúmulo de informações. Além de um conhecimento profundo de pedagogia e psicologia infantil, de sociologia da infância e de cultura da criança, associado a grande dose de experiência prática, a formação inicial deve incluir a educação do corpo, dos sentimentos, das emoções, da fala, da arte, do canto, do conto e do encanto. Uma educação fragmentada não produz eco na alma de uma criança.

Os depoimentos das participantes da pesquisa apontaram para a necessidade de integração entre os níveis de ensino; em se tratando da educação infantil, essa integração torna-se ainda mais emergencial no município pesquisado, por conta da forma como está estruturada a rede municipal de ensino, que divide a educação infantil em equipamentos diferentes.

Eu acho que antes da formação, falta integração! Acho que tem de começar lá de cima [Secretaria de Educação] a integrar isso! (Gestora Tatiana)

Exatamente! Você tem que começar a mudar o fluxo [...] Então a gente tem que começar mudando daí, da concepção, pra depois pensar no resto, na formação. (Professora Maria Clara)

Porque os professores hoje não sabem qual é a concepção. A prefeitura não tem uma concepção clara, o que ela quer para a educação infantil e nem para o fundamental!! Não há uma concepção de nada clara!! Nenhuma!! Cada um faz o que quer, o que acha correto. (Professora Mariana) 
Apesar de as professoras indicarem a necessidade de se esclarecer qual é a concepção de educação infantil da rede municipal - pois tal concepção não é clara para os professores -, consideram que a forma como a secretaria está organizada administrativamente já evidencia uma visão de criança, infância e educação infantil muito distante dos marcos legais e estudos da área, pois favorece dois tipos de cisão na primeira etapa da educação básica: a primeira, ao trilhar uma proposta pedagógica totalmente diferente entre as creches e as unidades que atendem crianças de 4 e 5 anos, diferentemente dos objetivos e princípios presentes nas DCNEI que compreendem de modo indissociável o trabalho educativo com as crianças de 0 a 5 anos e 11 meses; a segunda cisão refere-se à invisibilidade das especificidades da educação infantil e à priorização dos desafios e conteúdos do ensino fundamental como eixo do trabalho na educação infantil.

\section{Considerações finais}

Ao longo deste texto, buscaram-se evidenciar alguns elementos que configuraram os impactos presentes na prática cotidiana das instituições de educação infantil que atendem crianças de 4 e 5 anos após a implantação das Leis nº 11.114 e nº 11.274 (BRASIL, 2005, 2006), no município paulista pesquisado. Constatou-se a ocorrência de mudanças significativas na organização e estrutura das instituições, que ocorreram paulatinamente ao longo da última década, tais como a reestruturação do espaço físico que desconsidera as necessidades das crianças pequenas, a diminuição e quase exclusão dos jogos, brincadeiras e outras linguagens do cotidiano das crianças, e a ênfase acentuada em atividades de leitura e escrita, promovendo ações para a alfabetização precoce.

A intensificação das atividades de leitura e escrita com as crianças de 4 e 5 anos, no municipio pesquisado, decorrente da implantação das citadas leis federais, evidencia que essas práticas tornaram-se justificáveis e necessárias, desvelando a força da cultura escolar, a fragilidade da pré-escola e a negação das especificidades dessa etapa da educação básica.

Nesse sentido, pode-se afirmar que a implantação das referidas leis na rede de educação analisada, da maneira como foi realizada, colaborou para a acentuação do processo de colonização da educação infantil pelo ensino fundamental, tal como preconizado por Moss (2011) ao constatar que ações pedagógicas realizadas pelas turmas de 4 e 5 anos são atreladas aos objetivos do ensino fundamental.

A análise dos dados evidenciou a necessidade de o município pesquisado envidar esforços para repensar a política de educação infantil implementada, de modo a garantir que as diretrizes 
e a organização da Secretaria Municipal de Educação direcionem-se para a garantia dos direitos das crianças, em consonância com as DCNEI (CONSELHO NACIONAL DE EDUCAÇÃO, 2009). Também é imprescindível que haja uma integração dentro da própria educação infantil do município, unindo creche e pré-escola, para que, posteriormente, essa integração chegue ao ensino fundamental e haja continuidade educativa, respeitando as especificidades de cada etapa.

Ficou evidente que é essencial uma formação continuada com foco na especificidade e no fortalecimento da educação infantil, com vistas a uma ressignificação das práticas cotidianas e de modo a garantir que as brincadeiras e interações sejam os eixos norteadores da proposta curricular, conforme previsto nas DCNEI.

É preciso lembrar que o eixo fundamental para a constituição de políticas e práticas na educação infantil é o compromisso com a infância e os direitos fundamentais das crianças. É necessário não limitar esforços para legitimar a educação infantil, sua identidade e especificidades.

\section{Nota}

O município pesquisado adota a nomenclatura assistente pedagógico para o cargo de coordenador pedagógico.

\section{Referências}

ARELARO, Lisete Regina Gomes. O ensino fundamental no Brasil: avanços, perplexidades e tendências. Educação e Sociedade, Campinas, v. 26, n. 92, out. 2005. p. 1039-1066.

ARELARO, Lisete Regina Gomes; JACOMINI, Márcia Aparecida; KLEIN, Sylvie Bonifácio. O ensino fundamental de nove anos e o direito à educação. Educação e Pesquisa, São Paulo, v. 37, n. 1, jan./abr. 2011. p. 35-51.

BARBOSA, Maria Carmem Silveira; CRAIDY, Carmem Maria. Ingresso obrigatório no ensino fundamental aos 6 anos: falsa solução para um falso problema. In: BARBOSA, Maria Carmen Silveira; DELGADO, Ana Cristina Coll (Org.). A infância no ensino fundamental de nove anos. Porto Alegre: Penso, 2012. p. 19-36.

BARBOSA, Maria Carmen Silveira; DELGADO, Ana Cristina Coll (Org.). A infância no ensino fundamental de nove anos. Porto Alegre: Penso, 2012.

BARBOSA, Maria Carmen Silveira; DELGADO, Ana Cristina Coll; TOMÁS, Cristina Almeida. Estudos da infância, estudos da criança: quais campos? Quais teorias? Quais questões? Quais métodos? Inter-Ação, Goiânia, v. 41, n. 1, jan./abr. 2016. p. 103-122.

BRASIL. Constituição (1988). Constituição da República Federativa do Brasil de 1988. Promulgada em 5 de outubro de 1988. Brasília, DF, 1988. Disponível em: 
〈http://www.planalto.gov.br/ccivil_03/Constituicao/Constituicao.htm>. Acesso em: 9 abr. 2019.

BRASIL. Lei $n^{\circ} 11.114$, de 9 de maio de 2005. Altera os arts. 6º 30, 32 e 87 da Lei no .9 .394 , de 20 de dezembro de 1996, com o objetivo de tornar obrigatório o início do ensino fundamental aos seis anos de idade. Brasília, DF, 2005. Disponível em: 〈http://www.planalto.gov.br/ccivil_03/_Ato2004-2006/2005/Lei/L11114.htm>. Acesso em: 13 set. 2015.

BRASIL. Lei $n^{o} 11.274$, de 6 de fevereiro de 2006. Altera a redação dos arts. 29, 30, 32 e 87 da Lei n ${ }^{\circ}$ 9.394, de 20 de dezembro de 1996, dispondo sobre a duração de 9 (nove) anos para o ensino fundamental, com matrícula obrigatória a partir dos 6 (seis) anos de idade. Brasília, DF, 2006. Disponível em: <http://www.planalto.gov.br/ccivil_03/_Ato20042006/2006/Lei/L11274.htm>. Acesso em: 13 set. 2015.

CONSELHO NACIONAL DE EDUCAÇÃO. Câmara de Educação Básica. Resolução $C E B / C N E n^{\circ}$ 05/09, de 18 de dezembro de 2009. Fixa as Diretrizes Curriculares Nacionais para a Educação Infantil. Brasília, DF, 2009. Disponível em:

〈http://www.seduc.ro.gov.br/portal/legislacao/RESCNE005_2009.pdf >. Acesso em: 8 abr. 2019.

CORRÊA, Bianca Cristina. Considerações sobre qualidade na educação infantil. Educação $e$ Pesquisa, São Paulo, n. 119, jul. 2003. p. 85-112.

CORRÊA, Bianca Cristina. Educação infantil e ensino fundamental: desafios e desencontros na implantação de uma nova política. Educação e Pesquisa, São Paulo, v. 37, n. 1, jan./abr. 2011. p. 105-120.

CORSARO, Willian A. Sociologia da infância. Tradução Lia Gabriele Regius Reis. Porto Alegre: Artmed, 2011.

GATTI, Bernadete Angelina. Grupo focal na pesquisa em Ciências Humanas. Brasília, DF: Liber Livro, 2012.

HADDAD, Lenira. Políticas integradas de educação e cuidado infantil: desafios, armadilhas e possibilidades. Cadernos de Pesquisa, São Paulo, v. 36, n. 129, set./dez. 2006. p. 519-546.

HADDAD, Lenira. Substituir ou compartilhar? O papel das instituições de educação infantil no contexto da sociedade contemporânea. In: MACHADO, Maria Lúcia de A. (Org.). Encontros e desencontros em educação infantil. São Paulo: Cortez, 2002. p. 91-96.

HADDAD, Lenira. Tensões universais envolvendo a questão do currículo para a educação infantil. In: FRADE, Isabel Cristina Alves da Silva et al. Convergências e tensões no campo da formação e do trabalho docente. Belo Horizonte: Autêntica, 2010. p. 418-437.

KISHIMOTO, Tizuko Morchida. Brinquedos e brincadeiras na educação infantil. In: SEMINÁRIO NACIONAL DO CURRÍCULO EM MOVIMENTO: Perspectivas Atuais, 1., nov. 2010, Belo Horizonte. Anais eletrônicos... Disponíveis em: 〈http://portal.mec.gov.br/docman/dezembro-2010-pdf/7155-2-3-brinquedos-brincadeirastizuko-morchida/file>. Acesso em: 8 abr. 2019. 
KISHIMOTO, Tizuko Morchida. A pré-escola em São Paulo (1877 a 1940). São Paulo: Loyola, 1988.

KLEIN, Sylvie Bonifacio. Ensino fundamental de nove anos no município de São Paulo: um estudo de caso. 2011. 233 p. Dissertação (Mestrado em Educação) - Faculdade de Educação, Universidade de São Paulo, São Paulo, 2011. Disponível em:

〈http://www.teses.usp.br/teses/disponiveis/48/48134/tde-15072011-114221/pt-br.php>.

Acesso em: 8 abr. 2019.

KRAMER, Sônia. As crianças de 0 a 6 anos nas políticas educacionais no Brasil: educação infantil e/é fundamental. Educação e Sociedade, Campinas, v. 27, n. 96 (Especial), p. $797-$ 818 , out. 2006.

KRAMER, Sônia. A política do pré-escolar no Brasil: a arte do disfarce. Rio de Janeiro: Dois Pontos, 1987.

KRAMER; Sônia; NUNES, Maria Fernanda R.; CORSINO, Patrícia. Infância e crianças de 6 anos: desafios das transições na educação infantil e no ensino fundamental. Educação $e$ Pesquisa, São Paulo, v. 37, n. 1, jan./abr. 2011. p. 69-85.

MONÇÃO; Maria Aparecida Guedes. Gestão democrática na educação infantil: o compartilhamento da educação da criança pequena, 2013. Tese (Doutorado em Educação) Faculdade de Educação, Universidade de São Paulo, São Paulo, 2013.

MOSS, Peter. Qual o futuro da relação entre educação infantil e ensino obrigatório? Cadernos de Pesquisa, São Paulo, v. 41, n. 142, abr. 2011. p. 142-159.

SARMENTO, Manuel Jacinto; PINTO, Manuel. As culturas da infância nas encruzilhadas da $2^{\mathrm{a}}$ modernidade. In: SARMENTO, Manuel Jacinto; CERISARA, Ana Beatriz. Crianças e miúdos: perspectivas sociopedagógicas da infância e educação. Porto: ASA, 2004. p. 1-22. 